\title{
Sensitivities of species compositions of the mixed forest in eastern Eurasian continent to climate change
}

\author{
Guofan Shao ${ }^{\mathrm{a}, *}$, Xiaodong Yan ${ }^{\mathrm{b}}$, Harald Bugmann ${ }^{\mathrm{c}}$ \\ ${ }^{a}$ Institute of Applied Ecology, Chinese Academy of Sciences, 72 Wenhua Road, Shenyang 110015, PR China \\ ${ }^{\mathrm{b}}$ Institute of Atmospheric Physics, Chinese Academy of Sciences, Beijing 100029, PR China \\ ${ }^{\mathrm{c}}$ Department of Forest Sciences, Swiss Federal Institute of Technology, ETH-Zentrum HG G21.3, CH-8092 Zurich, Switzerland
}

Accepted 25 July 2002

\begin{abstract}
Sensitivities of species compositions of the broadleaf-conifer mixed forest in eastern Eurasian continent to climate change were evaluated with three forest gap models, namely KOPIDE, NEWCOP, and ForClim. Testing sites are located on Changbai Mountain, the middle of the distribution range for the mixed forest. Six climate change scenarios characterizing increase in temperature and increase/decrease in precipitation were used to test the sensitivities of species composition to climate change. Simulations suggest that the mixed forest in temperate Monsoon Asia will face changes in species composition should climate change be almost certain. At the minimum level, the order of dominant species is going to change due to species competition, resulting in the increase in the proportion of broadleaved tree species in the forest. If air temperature increases and precipitation decreases, Pinus koraiensis is going to disappear from the forest and the mixed forest will become hardwood forest. This experiment supports some earlier predictions under other climate change scenarios.
\end{abstract}

(C) 2003 Elsevier Science B.V. All rights reserved.

Keywords: Forest response; Broadleaf-conifer mixed forest; Climate change; Changbai Mountain

\section{Introduction}

The broadleaf-conifer mixed forest in temperate Monsoon Asia occurs in the cold area of the eastern Eurasian continent, covering the coastal areas of eastern Russia, the Korean Peninsula, and the eastern portion of northeastern China (Nakashizuka and Iida, 1995). For decades, this forest has been an important

* Corresponding author. Present address: Department of Forestry and Natural Resources, Purdue University, West Lafayette, IN 47907-1159, USA. Tel.: +1-765-494-3630; fax: +1-765-4962422.

E-mail address: gshao@fnr.purdue.edu (G. Shao). timber base in the region. Changbai Mountain, the core area of this vegetation zone, is covered with a large area of undisturbed temperate old-growth forest that is hardly found elsewhere on Earth (Shao and Zhao, 1998). The old-growth forest ecosystems provide important habitats for many endangered wildlife species, such as the Siberian tiger (Panthera tigris subsp. longipilis) and Chinese Qiusha Duck (Mergus sqatus). While these forests are well protected from cutting, they are facing potential impacts from global climate change.

Various efforts have been made to simulate structural responses of the mixed forest to climate change characterized with GCM-derived climate change sce- 
narios (e.g., Shao et al., 1995; Shao, 1996; Yan and Zhao, 1996; Yan et al., 1999). The climate change scenarios include GFDL (Manabe and Wetherald, 1987), GISS (Hansen et al., 1988), OSU (Schlesinger and Zhao, 1988), and UKMO (Mitchell, 1983). These climate change scenarios all predicted increases in temperature and precipitation in the region, and therefore, are not suitable for performing sensitivity tests. While global level changes in climate may or may not follow the general patterns predicted by the GCMs, local-level climate, which is regulated by physiographical environments, is even more difficult to predict. Sensitivity tests do not have to rely on the existing climate change scenarios and provide an alternative approach to understand the responses of forests to climate change. This paper addresses the sensitivities of mixed forest to climate change while another paper focused on model structures (Shao et al., 2001).

\section{Simulation experiments}

The study site is located on the north slope of Changbai Mountain, northeastern China (Fig. 1). Three locations at 740, 890 and $1040 \mathrm{~m}$, respectively, were chosen for the simulation experiments. Forests at these elevations represent typical broadleaf-conifer mixed forest in the east of the Eurasian continent. Climate data for the three locations were derived by interpolation between a meteorological station on the top of the mountain $(2700 \mathrm{~m})$ and one at $700 \mathrm{~m}$ on the north slope of the mountain. At each site, a time series of 600 years of monthly average temperature and monthly precipitation sum was generated by looping repeatedly through the past climate data between 1961 and 1995. It is assumed that the observed oldgrowth forests on the north slope of Changbai Mountain were developed under those climate conditions. From the simulation year 601 to 700 , a linear change of climatic parameters was assumed to take place, and 500 years representing a hypothetical future constant climate were used for characterizing the simulation years 701-1200, retaining the variability of current climate.

Three gap models, KOPIDE (Shao, 1989; Shao et al., 1994), NEWCOP (Yan and Zhao, 1996), and ForClim (Bugmann, 1994; 1996), were used to per-

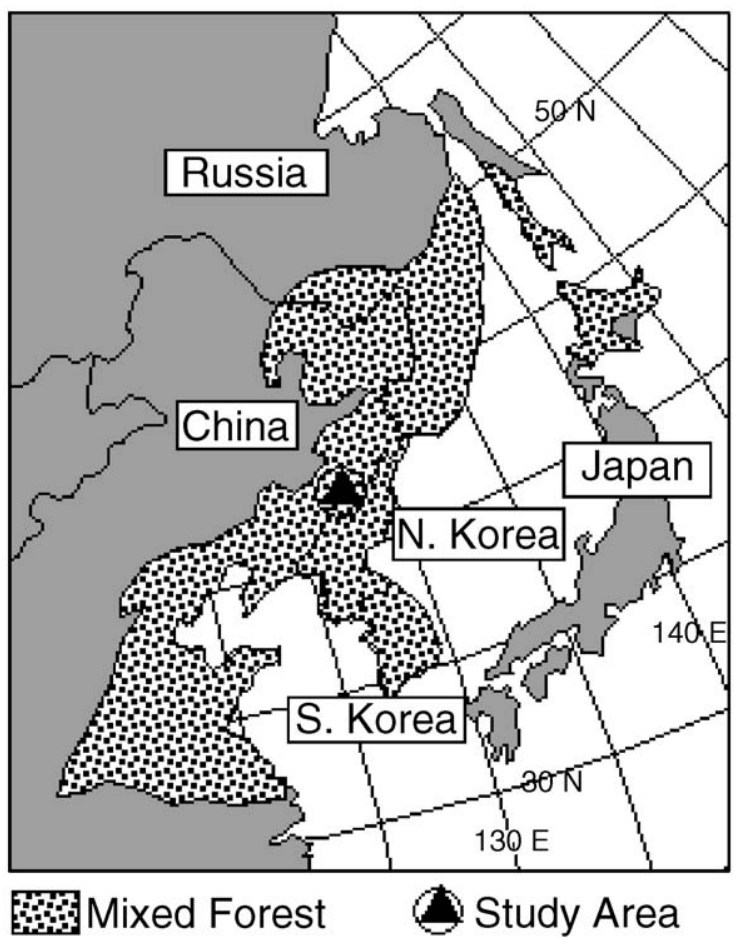

Fig. 1. The location of the study area is the middle of the broadleafconifer mixed forest (dotted area) in temperate Monsoon Asia. Refer to Nakashizuka and Iida (1995).

form simulation experiments. Because the original purpose of the simulations was to compare the three models, no efforts have been made to "fine-tune" the models. The parameterizations of ForClim were made by referring to NEWCOP. Two bioclimatic parameters could not be estimated for ForClim from NEWCOP dataset: the minimum winter temperature that is tolerated by a species, and the chilling requirement used for modifying establishment rates; thus, they were not included in this study. A total of up to 20 tree species were simulated (Table 1).

With 100 replicates in each experiment, each model was run at each site under current climate condition for 600 years (starting from bare ground) and another 600 years (following the initial 600 years) under six climate change scenarios (Table 2).

To explicitly compare stand structures among different simulations and between any simulations and reference data, basal area for the five most dominant species (with $>1 \mathrm{~m}^{2}$ stand basal area) were examined. 
Table 1

Tree species used $(\mathscr{\swarrow})$ in simulation experiments by three forest gap models

\begin{tabular}{|c|c|c|c|}
\hline Tree species & KOPIDE & NEWCOP & ForClim \\
\hline Abies holophylla & $\swarrow$ & 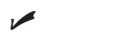 & $\swarrow$ \\
\hline Abies nephrolepis & $\swarrow$ & $\swarrow$ & $\swarrow$ \\
\hline Acer mono & $\swarrow$ & $\swarrow$ & $\swarrow$ \\
\hline Acer ukurunduense & - & $\swarrow$ & 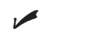 \\
\hline Betula platyphylla & - & 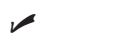 & $\swarrow$ \\
\hline Betula costata & - & $\swarrow$ & $\swarrow$ \\
\hline Betula dahurica & - & $\swarrow$ & $\swarrow$ \\
\hline Betula ermanii & - & $\swarrow$ & $\swarrow$ \\
\hline Fraxinus mandshurica & 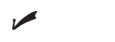 & $\mathscr{V}$ & 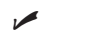 \\
\hline Juglans mandshurica & - & $\swarrow$ & $\swarrow$ \\
\hline Larix olgensis & - & $\swarrow$ & $\swarrow$ \\
\hline Phellodendron amurense & - & $\mathscr{\swarrow}$ & $\swarrow$ \\
\hline Picea jezoensis & $\swarrow$ & $\swarrow$ & $\swarrow$ \\
\hline Pinus koraiensis & $\swarrow$ & 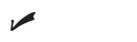 & $\swarrow$ \\
\hline Pinus changbaiensis & - & $\swarrow$ & 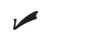 \\
\hline Populus ussuriensis & - & $\swarrow$ & $\prec$ \\
\hline Populus davidiana & 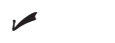 & $\swarrow$ & $\prec$ \\
\hline Quercus mongolica & $\swarrow$ & $\swarrow$ & $\swarrow$ \\
\hline Tilia amurensis & $\swarrow$ & $\swarrow$ & $\prec$ \\
\hline Ulmus japonica & $\swarrow$ & 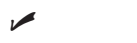 & 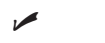 \\
\hline
\end{tabular}

The differences in dominant species composition between a prediction and reference data or between two predictions were quantified with a normalized distance:

$\mathrm{ND}_{i j}=\frac{1}{3.3} \frac{\left(N_{i j}+1\right)}{\left(n_{i j}+1\right)} \sum_{k=1}^{N_{i j}}\left(\left|S_{i k}-S_{j k}\right|\right)$

where $i$ and $j=$ forest $i$ and $j$, which are represented by model predictions or field observations; $n_{i j}=$ number of shared dominant species between two forests $\left(5 \leq n_{i j} \leq 0\right) ; N_{i j}=$ number of total dominant species

Table 2

Configurations of six climate change scenarios used in the simulation experiments

\begin{tabular}{lll}
\hline $\begin{array}{l}\text { Scenario } \\
\text { No. }\end{array}$ & $\begin{array}{l}\text { Changes in } \\
\text { temperature }\left({ }^{\circ} \mathrm{C}\right)\end{array}$ & $\begin{array}{l}\text { Changes in } \\
\text { precipitation }\end{array}$ \\
\hline 1 & +1.5 & no change \\
2 & +1.5 & $-10 \%$ \\
3 & +1.5 & $+10 \%$ \\
4 & +3.0 & no change \\
5 & +3.0 & $-10 \%$ \\
6 & +3.0 & $+10 \%$ \\
\hline
\end{tabular}

from both forests $\left(10 \leq N_{i j} \leq 1\right) ; S_{i k}$ and $S_{j k}=$ score of a dominant species $k$ in forest $i$ and $j$ : the value of 5 is assigned to the first dominant species, 4 to the second, $\ldots, 1$ to the fifth; and $\mathrm{ND}_{i j}=$ normalized distance of species composition between two forests $(0 \leq \mathrm{ND} \leq$ 100). The element $1 / 3.3$ is used for normalizing $\mathrm{ND}_{i j}$ values so that $\mathrm{ND}_{i j}=0$ when the number and order of dominant species are the same between two forests, and $\mathrm{ND}_{i j}=100(11 \times 30 / 3.3=100)$ when the five dominant species are completely different between two forests.

The ND characterizes the difference not only in species composition, but also in the order of dominant species even if two forests share the same dominant species. For example, if two forests share the same five dominant species but their orders are different, $\mathrm{ND}$ is about 3.6. In general, if ND is smaller than 5.0, two compared forests may be considered to share the same dominant species but have different orders of dominant species.

Reference data were independently obtained to validate simulations under the current climate. Data sources include earlier publications on old-growth forests in the Changbai Mountain area ( $\mathrm{Li}$ et al., 1981; Xu, 1992; Hao, 2000), and unpublished data collected from old-growth forests at or near the study sites. Since changes in temperature and precipitation from higher to lower elevations are similar to warmer and drier climate change scenarios, data from lower elevations are useful to evaluate model runs at higher elevations under climate change scenario 2 or 5 .

If a simulation includes 'fake' species in the list of the five most dominant species, the error is denoted as a 'commission error'; if a simulation excludes one or more species that dominate the forest in reality, the error is referred as an 'omission error' in this paper.

\section{Results}

Although the simulations did not perfectly predict dominant species compositions, some of the ND values are lower than 5 (Table 3 ). The simulations at 740 and $890 \mathrm{~m}$ were more reliable than those at $1040 \mathrm{~m}$. At the lower elevations, KOPIDE made the most accurate predictions (ND $=2.5-3.4$ ), NEWCOP the second $(\mathrm{ND}=4.8-6.4)$, and ForClim the third $(\mathrm{ND}=6.1)$. At these two sites, the most abundant tree 
Table 3

Scores $(S)$ of dominant species and ND values between observed and predicted species compositions

\begin{tabular}{|c|c|c|c|c|c|}
\hline Site & Species list & KOPIDE & NEWCOP & ForClim & Observed \\
\hline \multirow[t]{10}{*}{$1040 \mathrm{~m}$} & Pinus koraiensis & 5 & 3 & 5 & 5 \\
\hline & Tilia amurensis & 1 & & 3 & 4 \\
\hline & Acer mono & & & & 3 \\
\hline & Fraxinus mandshurica & & & & 2 \\
\hline & Picea jezoensis & 4 & 5 & 4 & 1 \\
\hline & Abies nephrolepis & 3 & 4 & & \\
\hline & Betula platyphylla & 2 & & & \\
\hline & Populus ussuriensis & & & 2 & \\
\hline & Betula costata & & & 1 & \\
\hline & ND & 9.7 & 13.4 & 7.3 & \\
\hline \multirow[t]{10}{*}{$890 \mathrm{~m}$} & Pinus koraiensis & 5 & 5 & 5 & 5 \\
\hline & Tilia amurensis & 2 & 4 & 3 & 4 \\
\hline & Acer mono & 3 & & & 3 \\
\hline & Fraxinus mandshurica & 4 & & 2 & 2 \\
\hline & Ulmus japonica & & & & 1 \\
\hline & Quercus mongolica & 1 & & & \\
\hline & Picea jezoensis & & & 4 & \\
\hline & Populus ussuriensis & & & 1 & \\
\hline & Betula costata & & 3 & & \\
\hline & ND & 2.5 & 6.4 & 6.1 & \\
\hline \multirow[t]{9}{*}{$740 \mathrm{~m}$} & Pinus koraiensis & 3 & 5 & 5 & 5 \\
\hline & Fraxinus mandshurica & 5 & 2 & 2 & 4 \\
\hline & Tilia amurensis & 4 & 4 & 3 & 3 \\
\hline & Quercus mongolica & & & & 2 \\
\hline & Ulmus japonica & 2 & & & 1 \\
\hline & Acer mono & 1 & & & \\
\hline & Picea jezoensis & & & 4 & \\
\hline & Betula costata & & 3 & 1 & \\
\hline & ND & 3.4 & 4.8 & 6.1 & \\
\hline
\end{tabular}

species in the measured forest is Korean pine. KOPIDE gives a poor result at $740 \mathrm{~m}$, where Fraxinus is simulated to be the most abundant species, whereas NEWCOP and ForClim give reasonably accurate results at 740 and $890 \mathrm{~m}$ with respect to the dominance of Korean pine. However, no model is successful in predicting the right order of the co-dominant tree species. At $1040 \mathrm{~m}$, ForClim's predictions were the most accurate, whereas NEWCOP's predictions were the most inaccurate. At all locations, each model has both commission and omission errors. The most conspicuous example for this is the inability of ForClim to exclude Picea from two lower elevation sites; NEWCOP strongly overestimates the share of coniferous species but missed some broadleaved tree species; all the three models missed Acer mono and Fraxinus mandshurica at $1040 \mathrm{~m}$.
Under climate change scenario 2, at the $890 \mathrm{~m}$ site, the KOPIDE model predicts Korean pine to disappear from the forest and to be replaced by hardwood species; Korean pine becomes less dominant but still exists in the NEWCOP simulations, and ForClim's predictions are the least sensitive; species composition stays essentially the same. The $1.5{ }^{\circ} \mathrm{C}$ increase in temperature and $10 \%$ decrease in precipitation at the $890 \mathrm{~m}$ site results in an annual mean temperature of $3.4{ }^{\circ} \mathrm{C}$ and an annual precipitation sum of $709 \mathrm{~mm}$, which are close to climate conditions at the $600 \mathrm{~m}$ site under the current climate where hardwood forests can grow. Therefore, the responses of dominant species to a warmer and drier climate predicted by KOPIDE were more reasonable than the responses of the other two models. 

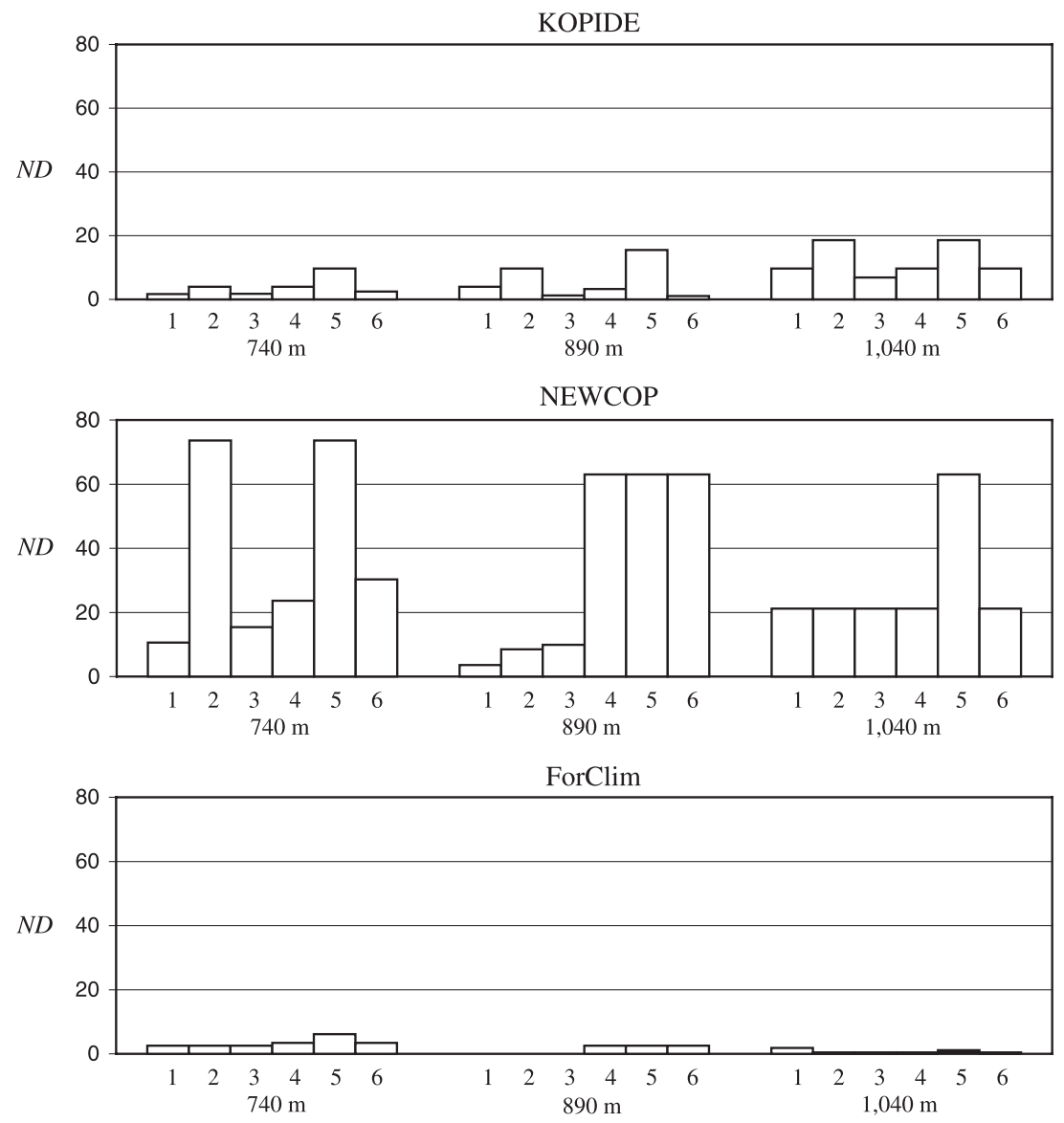

Fig. 2. The responses of tree species compositions (as quantified with ND) of three forest types to the six $(1,2, \ldots 6)$ climate change scenarios.

The responses of dominant species composition to the climate change scenarios are predicted differently by the three models (Fig. 2). Among the three models, ForClim predicts almost no species change (ND ranges from 0 to 6.1); NEWCOP suggests a lot of species replacement (ND ranges from 3.6 to 73.6); KOPIDE's behaviors are intermediate (ND ranges from 1.1 to 58.2), indicating some species replacement. At all sites, species composition is more sensitive to scenarios 4-6 than to $1-3$. KOPIDE's predictions are more sensitive to drier climate than to warmer climate as ND values under scenario 2 and 5 are much higher than those under other scenarios; NEWCOP's predictions are more sensitive to both drier and warmer climate; ForClim's predictions do not show much sensitivity. As elevation increases, KOPIDE's predictions become more sensitive to cli- mate changes, whereas NEWCOP's and ForClim's predictions become less sensitive.

\section{Discussion and conclusions}

Gap models contain site-specific biometric equations that characterize ecological processes and relationships (Bugmann, 2001). Unless systematic modifications are made to the models, valid applications in one location under certain conditions do not necessarily ensure their valid applications in other locations where forest and climate conditions are different. In this paper, the three models were developed with different backgrounds and for different purposes. They were never tested under warmer and drier climate conditions as demonstrated with scenarios 2 and 5. 
In addition to such extrapolations, ForClim was only partially parameterized in this study. All these changes resulted in some unrealistic behaviors, such as NEWCOP's high or ForCLim's low sensitivities to climate change. Based on comparisons with observed data, KOPIDE's predictions on dominant species compositions under the current and changed climate conditions are relatively accurate at lower elevations. This is partially because KOPIDE was developed specifically for the mixed forest at these elevations on Changbai Mountain.

The three forest gap models behaved differently. There are differences in the size of species pool, temperature-growth submodel, moisture-growth submodel, and patch size used among the three models (Shao et al., 2001). Larger species pool made models' behaviors more difficult to control and resulted in higher commission errors, the lack of chilling parameters in ForClim helped include Picea in the lower elevations; the high-sensitive drought constrains in NEWCOP caused strong responses in species composition under "dry" climate scenarios at the lower elevations; the relatively large patch size in NEWCOP and ForClim facilitated the regenerations of shadetolerant tree species but excluded oak and elm in the lower elevations. It is important to notice that all the shortcomings above barely exist in KOPIDE. This explains why KOPIDE's predictions are more convincing than the other two models for these simulation experiments, particularly in the lower elevations.

The broadleaf-conifer mixed forest in temperate Monsoon Asia will face changes in species composition should climate change be almost certain. At the minimum level, the order of dominant species is going to change, resulting in the increase in the proportions of broadleaved tree species in the forest. In this case, Pinus koraiensis still exists and it is not going to lose its dominant position. Because P. koraiensis is more sensitive to moisture, if air temperature increases and precipitation decreases, as indicated with scenario 2 or 5 , this tree species is going to disappear from the forest and the mixed forest will become hardwood forest. This prediction is similar to predictions under GFDL climate change scenario (Shao, 1996; Yan and Zhao, 1996).

The mixed forest ecosystems provide important habitats for many endangered plant and wildlife species. P. koraiensis is not only a dominant species, but also an indicator species of the mixed forest. The potential changes in forest structure and species composition will have important impacts on the quality and quantity of valuable plant and wildlife habitats. If $P$. koraiensis disappears from the forest, the food web will be changed as pine nuts provide important food sources for rodent species. The mixed forest also functions as timber production base in the region. $P$. koraiensis has been extensively used by the wood industry because of some of its unique features of wood quality. Tree plantations of $P$. koraiensis are still common after clear-cutting of the mixed forest. This silviculture practice needs to be modified as climate becomes warmer and drier.

\section{Acknowledgements}

This study was funded in part by the Chinese Academy of Sciences (KZ95T-04, KZ951-A1-301, "100 Outstanding Scientists Project"). The authors thank their home institutions for providing resources while writing this paper. Dr. Limin Dai, Dr. Zhanqing Hao, and Dr. Hongbing Ding from the Changbai Mountain Forest System Research Station of Chinese Academy of Sciences helped collect or provided field data that were used for running and validating models in this paper. The authors also thank constructive comments from anonymous reviewers.

\section{References}

Bugmann, H., 1994. On the ecology of mountainous forests in a changing climate: a simulation study. PhD thesis No. 10638. Swiss Federal Institute of Technology Zürich, Switzerland. 258 pp.

Bugmann, H., 1996. A simplified forest model to study species composition along climate gradients. Ecology 77, 2055-2074.

Bugmann, H., 2001. A review of forest gap models. Climatic Change 51, 295-305.

Hansen, J., Fung, I., Rind, D., Russell, G., Lebedeff, S., Reudy, R., Stone, P., 1988. Global climatic changes as forecast by the GISS3-D model. Journal of Geophysical Research 93, 9341-9364.

Hao, Z., 2000. Analysis of plant community diversities and their gradient patterns on the northern slope of Changbai Mountain, Northeast China. PhD dissertation, Chinese Academy of Sciences, p. 28. In Chinese.

Li, W., Li, F., Han, J., 1981. Study on biomass and primary production of main ecosystems in Changbai Mountain. Research of Forest Ecosystems 2, 34-50 (in Chinese). 
Manabe, S., Wetherald, R.T., 1987. Large scale changes in soil wetness induced by an increase in carbon dioxide. Journal of Atmospheric Sciences 44, 1211-1235.

Mitchell, J.F.B., 1983. The seasonal response of a general circulation model to changes in $\mathrm{CO}_{2}$ and sea temperature. Quarterly Journal of the Royal Meteorological Society 109, 113-152.

Nakashizuka, T., Iida, S., 1995. Composition, dynamics and disturbance regime of temperate deciduous forests in Monsoon Asia. Vegetatio 121, 23-30.

Schlesinger, M., Zhao, Z., 1988. Seasonal Climatic Changes Induced by Doubled $\mathrm{CO}_{2}$ as Simulated by the OSU Atmospheric GCM/Mixed Layer Ocean Model. Climate Research Institute, Oregon State University, Corvallis, OR.

Shao, G., 1989. KOPIDE: a computer model of forest growth and succession on Changbai Mountain. PhD dissertation. Chinese Academy of Sciences. 158 pp. (in Chinese).

Shao, G., 1996. Potential impacts of climate change on a mixed broadleaved-Korean pine forest stand: a gap model approach. Climatic Change 34, 263-268.

Shao, G., Zhao, G., 1998. Protecting versus harvesting of oldgrowth forests on the Changbai Mountain (China and North Korea): a remote sensing application. Natural Areas Journal $18,334-341$.
Shao, G., Schall, P., Weishampel, J.F., 1994. Dynamic simulations of mixed broadleaved-Pinus koraiensis forests in the Changbaishan Biosphere Reserve of China. Forest Ecology and Management 70, 169-181.

Shao, G., Shugart, H.H., Smith, T.M., 1995. A role-type model (rope) and its application in assessing climate change impacts on forest landscapes. Vegetatio 121, 135-146.

Shao, G., Bugmann, H., Yan, X., 2001. A comparative analysis of the structure and behavior of three gap models at sites in northeastern China. Climatic Change 51, 389-413.

$\mathrm{Xu}, \mathrm{Z}$., 1992. Periodic review of forest ecosystem researched at Changbai Mountain: 1979-1985. Research of Forest Ecosystems 6, 25-42.

Yan, X., Zhao, S., 1996. Simulating Changbai Mt. forests with climate change. Journal of Environmental Science 8, 358-368 (in Chinese).

Yan, X., Zhao, S., Shugart, H.H., Fu, C., Yu, Z., 1999. How should the Xiao Hinggan Mt. forests change with potential climate change: a simulation study. Journal of Natural Resources 14, 372-376 (in Chinese). 